Témoigner Témoigner. Entre histoire et mémoire

Getuigen Revue pluridisciplinaire de la Fondation Auschwitz

$121 \mid 2015$

Violences radicales en scène

\title{
Belgique : Episode 3 - Exposer 14-18 en Belgique
}

België: aflevering 3 - 14-18: Tentoongesteld in België

\section{Eléonore Buyse et Karla Vanraepenbusch}

\section{(2) OpenEdition}

\section{Journals}

Édition électronique

URL : https://journals.openedition.org/temoigner/3624

DOI : 10.4000/temoigner.3624

ISSN : 2506-6390

Traduction(s) :

België: Aflevering 3 - 14-18 tentoongesteld in België - URL : https://journals.openedition.org/ temoigner/3634 [nl]

Éditeur :

Éditions du Centre d'études et de documentation Mémoire d'Auschwitz, Éditions Kimé

Édition imprimée

Date de publication : 1 octobre 2015

Pagination : 196-198

ISSN : 2031-4183

Référence électronique

Eléonore Buyse et Karla Vanraepenbusch, «Belgique : Episode 3 - Exposer 14-18 en Belgique », Témoigner. Entre histoire et mémoire [En ligne], 121 | 2015, mis en ligne le 01 octobre 2016, consulté le 04 février 2022. URL : http://journals.openedition.org/temoigner/3624 ; DOI : https://doi.org/10.4000/ temoigner.3624 


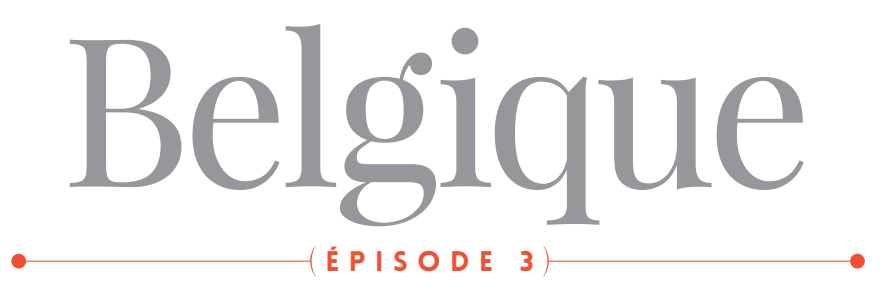

\section{EXPOSER 14-18 EN BELGIQUE}

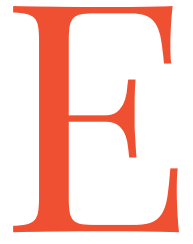

n Belgique, le centenaire de la Grande Guerre constitue un événement commémoratif d'une ampleur sans précédent. Ainsi, le début du centenaire a vu l'organisation de plusieurs expositions temporaires sur la Première Guerre mondiale. La plupart d'entre elles retracent l'histoire locale du conflit, soit de la région du front de l'Yser dans le Westhoek, soit des villes martyres ou encore des villes et villages belges envahis puis occupés par les Allemands. Quelquesunes se structurent également autour d'un aspect bien défini du conflit, tel que les ravages, la photographie, l'invasion ou les attaques aux gaz.

Seules deux expositions temporaires ont eu l'ambition de se positionner comme des expositions de synthèse et de présenter la dimension belge et européenne du conflit. À Bruxelles, l'exposition «14-18, c'est notre histoire ! » se déroule au Musée royal de l’Armée et d'Histoire militaire du 26 février 2014 jusqu'au 15 novembre 2015. L'exposition « J'avais 20 ans en 14 » a lieu à la gare de Liège-Guillemins du 2 août 2014 jusqu'au 30 août 2015.

Le fait qu'aucune de ces deux expositions de synthèse ne provienne du nord du pays relève de la différence dans l'approche commémorative existant entre les autorités flamandes d'une part et les autorités wallonnes et bruxelloises d'autre part (Bost ; Kesteloot, 2014). En focalisant leurs commémorations sur l'expérience du front, le Westhoek et les batailles de l'Yser, les autorités flamandes souhaitent faire de la
Flandre une destination phare du tourisme de guerre. Les autorités francophones ont plutôt cherché à faire de leurs commémorations un microcosme de l'expérience belge de la guerre. Celles-ci traitent du conflit dans ses composantes multiples, abordant aussi bien les expériences de guerre des combattants que celles des civils, ce qui se reflète dans les expositions « 14-18, c'est notre histoire ! » et « J'avais 20 ans en 14 ».

\section{BLOCKBUSTER}

«14-18, c'est notre histoire! » et « J'avais 20 ans en 14 » sont des expositions dites «blockbuster». Terme anglais utilisé au départ pour indiquer les films à grand budget et à succès, il s'applique depuis les années 1980 aussi aux méga-expositions qui génèrent dans un temps limité un nombre record de visiteurs (Desvallées ; Mairesse, 2011). Ces deux expositions 14-18, qui se déroulent respectivement sur une surface de $2500 \mathrm{~m}^{2}$ et $4000 \mathrm{~m}^{2}$, sont effectivement des expos fortement fréquentées ${ }^{1}$. Elles ont fait l'objet d'une bonne couverture médiatique, ce qui renforce le sentiment de nécessité de les avoir vues, de nécessité de les avoir adorées ou détestées.

Ce type d'exposition contribue sans doute à la démocratisation de la culture et de l'histoire. Cependant, il y a aussi des enjeux qui se posent. Les concepteurs d'une exposition blockbuster font généralement le choix d'une valeur sûre en termes de fréquentation, telle que Toutankhamon ou Van Gogh, au détriment 


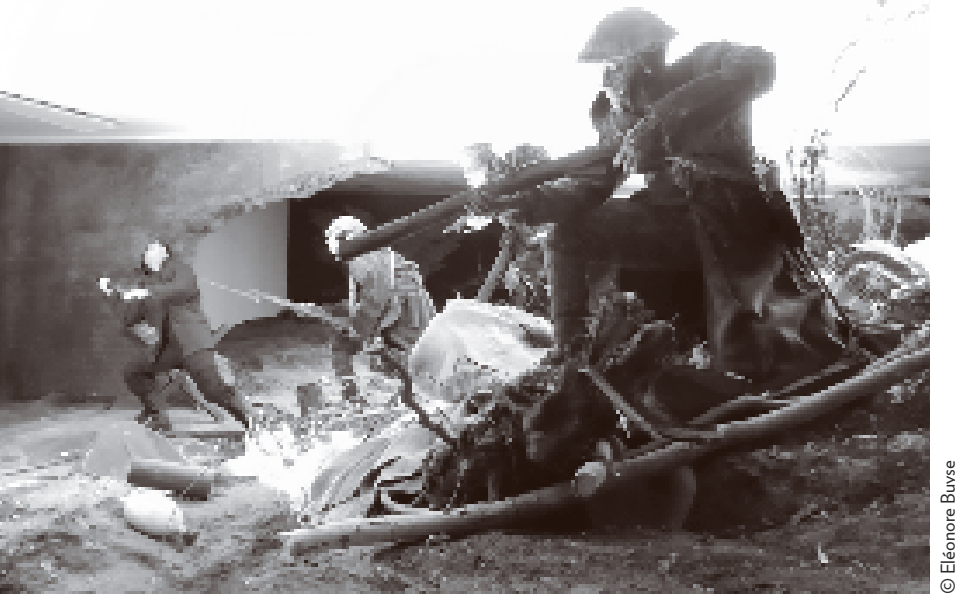

_ Exposition « J'avais 20 ans en 14 » (Liège).

de thématiques plus originales. Dans le cas de l'exposition liégeoise et bruxelloise, il s'agit de deux agences de communication, Europe 50 et Tempora, qui ont, dans le cadre du centenaire de la Grande Guerre, créé une exposition sur un événement fort médiatisé. La Première Guerre mondiale est alors présentée au grand public de façon neutre et dépolitisée, même si celle-ci se caractérise par une mémoire vivante qui influence la politique belge jusqu'à aujourd'hui.

La scénographie risque en outre de l'emporter sur le contenu et sur les objets exposés. « J'avais 20 ans en 14 » par exemple est une vraie exposition spectacle. Les visiteurs sont plongés dans l'ambiance de l'époque au travers de décors reconstitués, d'effets sonores et lumineux. Des vitrines mettant en valeur des objets authentiques sont par ailleurs aussi présentes. L'exposition bruxelloise «14-18, c'est notre histoire ! » combine également une approche immersive et une approche centrée sur l'objet authentique, en y ajoutant l'interactivité informatique. La participation émotionnelle du visiteur est sollicitée, mais pas de manière aussi théâtrale et spectaculaire qu’à Liège.

\section{L'EXPÉRIENCE DE GUERRE DES COMBATTANTS}

Pour présenter au visiteur ce qu'a pu être l'expérience des combattants, les deux expositions tentent de plonger celui-ci dans la vie quotidienne des soldats. Afin de souligner tant la rigueur des combats que les périodes d'attente et de repli entre deux montées sur la ligne de front, du matériel de combat (armes, uniformes, casques...) côtoie des objets plus anodins, utilisés jour après jour (correspondance, cigarettes, artisanat...). Même si elle est davantage présente à Liège, les deux expositions n'éludent pas la question de la mort, à laquelle le visiteur est confronté lorsqu'il se retrouve face à des photos de corps inanimés.

Des commentaires audio en plusieurs langues accompagnentégalement des montages photos. Lettres et écrits de soldats sont lus en plusieurs langues, constituant ainsi des témoignages réels de l'expérience des combattants. Afin de procurer au visiteur une image concrète, des décors à taille réelle ont été construits dans chaque exposition. Cependant, tandis que l'exposition bruxelloise donne à voir la reconstitution d'une tranchée sobre, l'exposition de Liège contient de vastes décors de tranchée et de champs de bataille, « réalistes » et dramatiques, car agrémentés de sons et lumières.

« J'avais 20 ans en 14 » se clôture en outre sur une grande place laissée à la thématique des gueules cassées et aux traumatismes liés à la guerre, laissant sousentendre que l'expérience des combattants ne se limite pas aux quatre années de guerre, mais que celle-ci abel et bien changé leur vie à jamais.

\section{L'EXPÉRIENCE DE GUERRE DES CIVILS}

L'expérience de guerre des civils est toute aussi présente dans les deux expositions que celle des combattants. Elles mettent chacune en lumière le lourd tribut que la population civile a payé à la guerre. À Liège, le scénario de l'exposition développe principalement les personnages du civil et du résistant, et le parcours amène le visiteur d'un décor reconstitué à l'autre : une scène d'exécution, des maisons bombardées et incendiées (avec cris d'enfant) et la ligne électrifiée entre la Belgique et les Pays-Bas. À Bruxelles, une salle donne à voir, sur une carte géante de la Belgique étendue sur le sol, l'avancée des troupes allemandes lors de l'invasion. Grâce à des bornes interactives, les visiteurs peuvent s'informer davantage sur les exactions qui ont eu lieu dans les différentes régions. Le visiteur retrouve également de nombreux décors évoquant les rapports entre occupants et occupés : une Kommandantur, un magasin américain, un bistrot, la prison dans laquelle étaient détenus les résistants. 
-. Ces deux expositions de référence sur l'histoire de la Grande Guerre représentent clairement les civils comme des victimes et comme des hommes et des femmes résistant à l'ennemi. Seules quelques petites vitrines d'objets et de documents dans l'exposition bruxelloise présentent superficiellement le point de vue de ceux qui ont économiquement profité de la guerre ou qui ont idéologiquement soutenu l'ennemi. À Liège, le visiteur ne trouve aucune trace d'un quelconque acte anti-patriotique dans le parcours de l'exposition « J'avais 20 ans en 14 ». Tous les Belges semblent avoir été de bons citoyens, alors que nombre d'entre eux ont été condamnés pour incivisme après la guerre.

\section{LA DIMENSION BELGE}

\section{ET EUROPÉENNE DU CONFLIT}

La dynamique de ces deux expositions est bel et bien de présenter la Grande Guerre comme un conflit ayant touchél'humanité sans distinction de nationalité ou de niveau social. Ainsi, les légendes lacunaires des photographies exposées permettent rarement d'identifier la nationalité des soldats. Ce souhait de ne pas faire de distinction est également perceptible dans les commentaires audio puisque la parole est donnée tant à des soldats francophones, néerlandophones et anglophones que germanophones. À côté des uniformes belges se trouvent présentés de nombreux uniformes étrangers. Dans la même logique d'inclusion, il est souligné que le manque de nourriture et les restrictions touchaient toutes les populations, qu'elles soient belges ou allemandes.

Ces deux expositions illustrent en effet l'idéal d'un humanisme européen abstrait. Ce message semble parfois un brin trop naïf, comme l'a remarqué Marc Reynebeau (Reynebeau, 2014). L'exemple le plus flagrant de cette naïveté étant sans doute le film auquel le visiteur est confronté à la fin de la visite de l'exposition «14-18, c'est notre histoire! ». Celui-ci montre, à un rythme effréné, des images de l'histoire violente du XXI ${ }^{\mathrm{e}}$ siècle, culminant en l'obtention du Prix Nobel de la Paix par l’Union européenne. Ce narratif rassurant et trop simpliste implique que l'Europe connaît aujourd'hui la paix, alors que l'actualité démontre clairement que cela n'est pas le cas.

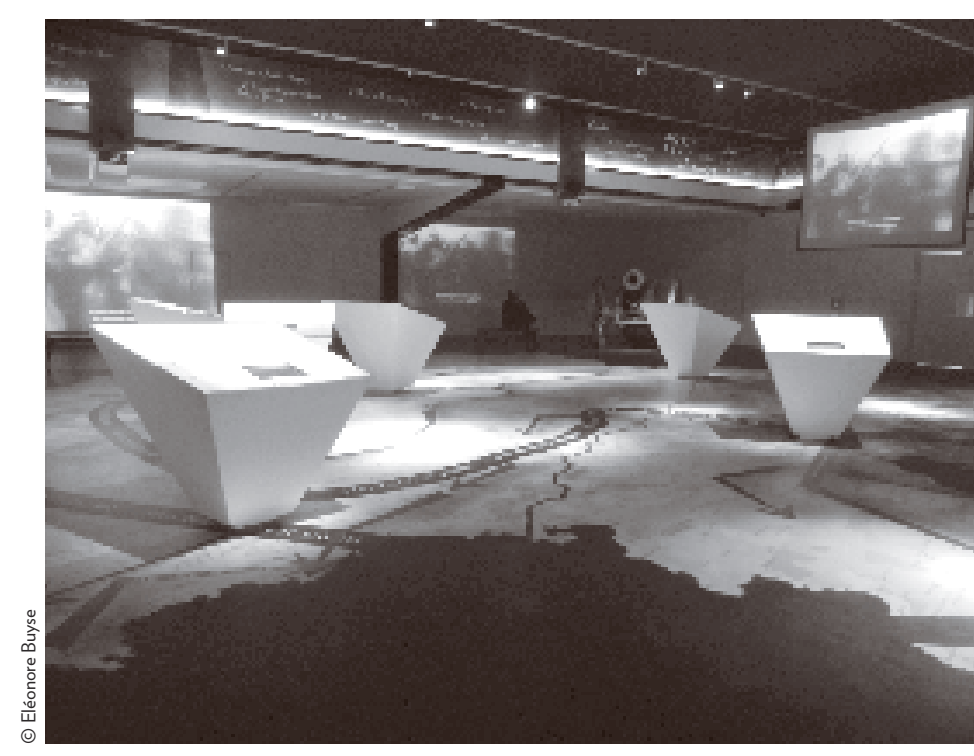

_ Exposition « 14-18, c'est notre histoire !» (Bruxelles).

Ce message démine en quelque sorte la mémoire belge de la Grande Guerre de ses enjeux politiques et idéologiques. Nulle part n'est expliqué le rôle fondamental du conflit dans la mémoire du mouvement flamand. En outre, les deux expositions présentent la Belgique comme une nation ayant été victime d'une violation du droit international, mais défendue par l'entièreté de sa population, sans jamais prendre en compte ceux qui ont soutenu l'ennemi ni leurs motivations. I

Eléonore Buyse et Karla Vanraepenbusch

\section{BIBLIOGRAPHIE}

- Bost, Mélanie ; Kesteloot, Chantal (2014).

Les commémorations du centenaire de la Première Guerre mondiale, Bruxelles, Courrier hebdomadaire du CRISP.

- Desvallées, André ; Mairesse, François, (2011) : Dictionnaire encyclopédique de muséologie, Paris, Armand Colin, p. 572.

- Reynebeau, Marc (26 février 2014) : «De Eerste Wereldoorlog voor en achter het front. "Expo 14-18, Dit is onze geschiedenis!": het uitroepteken zegt al veel », in De Standaard. 